\title{
Analysis on the Impact of Renewable Energy to Power System Fault Level
}

\author{
A. Z. Adnan, M. E. Yusoff, H. Hashim
}

Universiti Tenaga Nasional, Putrajaya Campus, 43000 Kajang Selangor, Malaysia

\begin{tabular}{l}
\hline \hline Article Info \\
\hline Article history: \\
Received Apr 1, 2018 \\
Revised Jun 20, 2018 \\
Accepted Jul 7, 2018 \\
\hline
\end{tabular}

\section{Keywords:}

Distributed

Fault Level

Generation

Solar PV

\begin{abstract}
Distributed Generation is generation of electricity from renewable energy resources, located closer to the customers or loads. Installation of Distributed Generation could improve voltage and power quality, mitigate voltage sags, minimize transmission system congestion, and provide more affordable capacity for utilizing renewable energy resources. However, high penetration of Distributed Generation to the existing national grid system may contribute several impacts including fault level, as well as the performance of power system protection. Monitoring of fault level is important in power system protection in order to sustain the health of power system networks. This paper investigates the impact of installing Distributed Generation to power system fault level. Three-phase symmetrical fault is simulated and analyzed for various sizes of distributed generation in IEEE 30 bus system using Power System Simulation for Engineering (PSS/E) software.
\end{abstract}

Copyright @ 2018 Institute of Advanced Engineering and Science. All rights reserved.

\section{Corresponding Author:}

\author{
A. Z. Adnan \\ Universiti Tenaga Nasional, \\ Putrajaya Campus, 43000 Kajang Selangor, Malaysia \\ Email: aisya_zulaikha17@yahoo.com
}

\section{INTRODUCTION}

A distribution network that has smooth operation, continuous power supply or less power interruption are the factors that mainly contribute to power system reliability [1]. Distributed generation (DG) is one of the way to generate electricity and maintain the sustainability of power generation while reduces the climate change effect; the energy resources of DG are from renewable energy (RE) [2-5].

Advantages of DG such as unloading sub-transmission and transmission system, improving voltage profile, decreasing system losses, enhancing power quality and reliability can be affected by the system and installation of DG [6-8]. However, different level of DG penetration may bring various drawbacks to power system such as harmonics, voltage sags steady state voltage rise, flickers, frequency instability and increase of short circuit current or fault level, causing damage to the plant and interruption of power supply [1], [6-7] [9-12]. Therefore, power system fault level should be monitored in order to maintain the reliability of protection equipment and availability of power supply to the customers. Two main factors that influence the impact of DG to power system reliability: first, the characteristic of distribution networks such as line impedance and system load [6] and second the DG itself such as type, location and size of DG that is to be connected to power system network [6-7], [11], [13-14].

\section{DISTRIBUTED GENERATION (DG)}

Distributed generation (DG) is a compilation of small generation or generators that are located either near the utility site or the consumers at distribution level [6], [15]. Generators can be conventional such as coal, fuel oil, and hydro powered synchronous machine as well as sources that includes emerging technology for example wind turbines, microturbines, fuel cells and solar photovoltaics (PV). DC source such as PV 
require a Power Generation Unit (PGU) to generates DC power and converts to AC via inverter [6]. The control scheme of the inverter maintains the output voltage, active and reactive power to match the desired predetermined set points and feedback to PWM generator for correct modulation index. If different type of DG connected to the network, it wil become more complex in terms of fault current response which should be considered in investigating DG integration effects on the grid [16-17]. This project is focusing on solar PV because of the tropical climate in Malaysia, which has become a popular renewable energy in Malaysia as it has limitless resource, zero green gas emission and capable to electrify rural areas without accessing the grid [18]. The penetration of solar PV system in electrical distribution networks can bring many benefits, which includes reduction of electrical losses, improving the stability and reliability of the distribution system, and reducing transmission line costs [9]. However, its weather-dependency and low efficiency of PV panels are the disadvancetages of solar energy consumption including extensive integration of PV distributed generation (PVDG) into distribution networks can result into disruption of the normal operation [18-19].

\section{IMPACTS OF DISTRIBUTED GENERATORS}

The main purpose of distributed generators integration is to generate a capacity amount required by the load and the grid. Based on other research works, high level of DG penetration is likely to give a negative impact to the grid; change of voltage profile along the distribution network, increase in short circuit level, voltage transients due to connection and disconnection of DG, distruption in power quality and reliability of the system including overloading of lines and equipment that leads to thermal overloading. The severity of these issues depends on the penetration level of solar PV, the load characteristics, distribution system configuration and the location of solar PV in distribution system as shown in previous researchs [6-7], [11], [13- 14]. Results obtained from previous research have shown that 25\% DG penetration improves the transient stability of the grid, while the connection and high penetration of DG causes disturbance such as increase in fault level and affect power system protection performance [4], [11], [23].

\section{METHODOLOGY}

IEEE30 bus test system is modelled using PSSE software as shown in Fig. 1; the network is divided into three areas. The details about the networks are shown in Table 1 . The test system consists of six generators, having two generators located at each area and the total generating is almost $200 \mathrm{MW}$. Based on Malaysia Energy Commission for Large Scale Solar (LSS), a minimum of $1 \mathrm{MW}$ and a maximum of $50 \mathrm{MW}$ can be connected to distribution network [24]. Hence, $5 \mathrm{MW}$ and $10 \mathrm{MW}$ of PV are used in this research work.

Table 1. Details on IEEE 30 Bus Test System

\begin{tabular}{cccc}
\hline Items & Brea 1 & Bus Number & Area 2 \\
\hline Generator Bus & 1,2 & 13,23 & 22,27 \\
Load Bus & $2,3,4,7,8$ & $12,14,15,16,17,18$, & $10,21,24,26,29,30$ \\
& & $19,20,23$ & 24 \\
Fixed Shunt & 5 & 19 & $22,24,26$, \\
Bus at Respective Area & $1,2,3,4,5,6,7,8,9$, & $12,13,14,15,16,17$, & $10,21,22,24,25,30$ \\
\hline
\end{tabular}

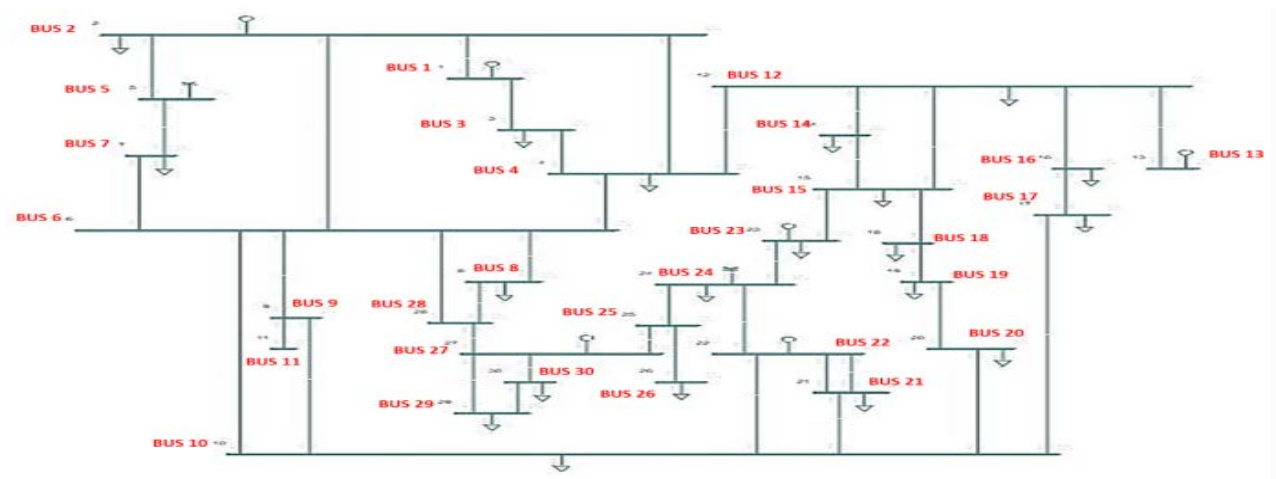

Figure 1. IEEE30 Bus Test System 
The flow chart in Figure 2 shows the methodology on fault analysis of this research work. Three phase symmetrical fault is simulated at three different buses which are Bus 8, Bus 20 and Bus 29 respectively. The selected buses for the fault to occur are based on the concentration of the loads and location of DG in the system. Figure 3 demonstrates this time line event; bus fault is applied into the test system at $1 \mathrm{~s}$ and cleared after $150 \mathrm{~ms}$ with connected lines are tripped.

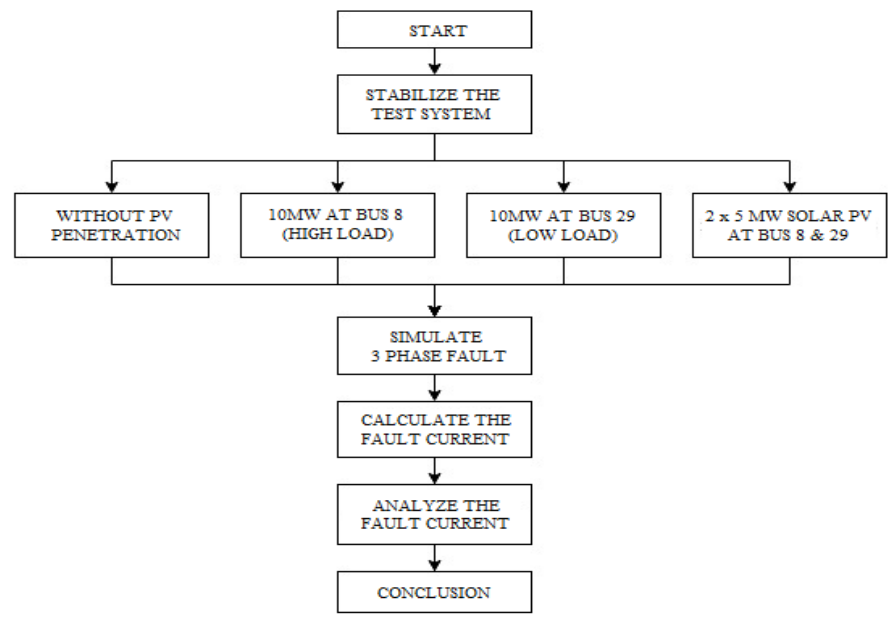

Figure 2. Fault Level Analysis

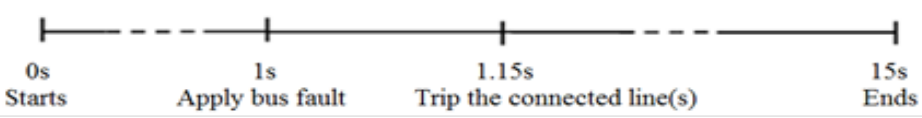

Figure 3. Time Line Events

Based on PSSE simulation results, the magnitude of the three phase symmetrical fault is calculated during the sub-transient and transient fault conditions with and without the presence of DG for different size and location of DG, and at three different fault locations. Below are the scenarios of the research work:

a. Scenario 1: Without solar PV Penetration

b. Scenario 2: $10 \mathrm{MW}$ solar PV at Bus 8 with high load

c. Scenario 3: $10 \mathrm{MW}$ solar PV at Bus 29 with low load

d. Scenario 4: 2 X 5 MW solar PV at Bus 8 \& 29

\section{RESULTS AND ANALYSIS}

The PSSE simulation results are presented based on the scenario, starting with analysis on the magnitude at sub-transient condition followed by transient condition.

\subsection{Sub-transient Condition}

Sub-transient fault usually occurs after $10 \mathrm{~ms}$ until $20 \mathrm{~ms}$ after the occurrence of fault. During this period, maximum possible current flows immediately after fault is used to design the circuit breaker rating and the protective relay to operate. The sub-transient short circuit current for this research work is taken at $1.015 \mathrm{~s}$ which is $15 \mathrm{~ms}$ after the fault occurs. Table 2 shows the short circuit MVA values based on PSS/E simulation results when fault takes place at Bus 8, Bus 20 and Bus 29 respectively for all scenario. The fault levels increase at locations near to the injection point of solar PV at Bus 20 and Bus 29 at Scenario 3 and decreases at Scenario 4. Comparing with the scenario without PV penetration, the fault level at Bus 8 also increases and it has the highest fault level at Scenario 2. 
Table 2. Short Circuit Values for Sub-Transient Fault Current

\begin{tabular}{ccccc}
\hline Fault at Bus & \multicolumn{4}{c}{ Short Circuit MVA, S } \\
& Scenario 1 & Scenario 2 & Scenario 3 & Scenario 4 \\
\hline 8 (Area 1) & 261.5835 & 268.6133 & 264.2953 & 265.4978 \\
20 (Area 2) & 191.7838 & 199.4488 & 200.1880 & 198.6961 \\
29 (Area 3) & 141.1396 & 143.4929 & 144.8220 & 139.0304 \\
\hline
\end{tabular}

\subsection{Transient Fault Current}

In this section, the fault current will be determined at transient level. Transient fault may end up until 150ms after the occurrence of fault. During this period, the critical clearing angle and time are determined to ensure that the fault is cleared before the system running out stability. The transient short circuit current $(\mathrm{kA})$ for this research work is taken at 1.09 seconds which is $90 \mathrm{~ms}$ after the fault occur. Table 3 shows the short circuit values in transient conditions for all scenario. Based on Table 3, Bus 8 has the highest amount of fault level at Scenario 2 compare to other scenarios. The fault level at this conditions is lower than the sub-transient codition as the values can be compare in Table 2.

Table 3. Short Circuit Values for Transient Fault Current.

\begin{tabular}{ccccc}
\hline Fault at Bus & \multicolumn{4}{c}{ Short Circuit MVA, S } \\
& Scenario 1 & Scenario 2 & Scenario 3 & Scenario 4 \\
\hline 8 (Area 1) & 237.9133 & 247.2424 & 242.3908 & 244.9853 \\
20 (Area 2) & 183.8069 & 188.2511 & 188.1519 & 190.5395 \\
29 (Area 3) & 130.1012 & 133.7585 & 134.2601 & 129.9708 \\
\hline
\end{tabular}

\subsection{Overall Comparison between Scenarios}

The magnitude of the fault currents is calculated based on the short circuit MVA for each scenario. Comparisons are made between all the four scenarios for both the sub-transient and transient conditions. Table 4 and Table 5 show the summary of all fault current values for four different scenarios at sub-transient and transient fault conditions. While Table 5, the increment of fault current is calculated taking scenario without PV penetration as the reference so as to compare with other scenarios during sub-transient and transient conditions.

\subsubsection{Comparison of Fault Current Scenario at Sub-Transient and Transient Conditions}

Table 4 and Table 5 have proven that for all scenarios and at all fault locations for sub-transient and transient conditions, there is an increased in fault level when there is solar PV penetration into the network. For Bus 8, the highest increment is when solar PV is injected at Bus 8 during sub-transient condition for all scenarios; similar result applies to Bus 29 during transient condition for scenario 3 and 4. However, when solar PV with the same amount of power connected to Bus 8 and Bus 29, the fault levels slightly reduce between those two conditions.

Table 4. Fault Current at Sub-Transient and Transient Condition

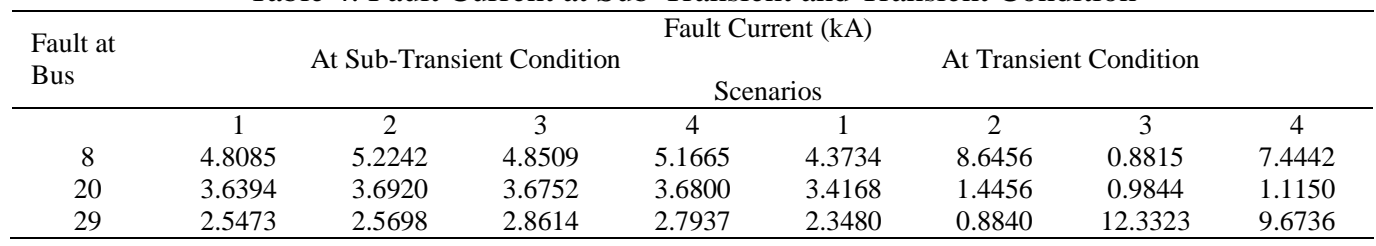

Table 5. Increment of Fault Current

\begin{tabular}{ccccccc}
\hline \multirow{2}{*}{$\begin{array}{l}\text { Fault at } \\
\text { Bus }\end{array}$} & \multicolumn{5}{c}{ Increment of Fault Current (\%) } \\
& \multicolumn{2}{c}{ At Sub-Transient Condition } & \multicolumn{3}{c}{ At Transient Condition } \\
& Scenario 2 & Scenario 3 & Scenario 4 & Scenario 2 & Scenario 3 & Scenario 4 \\
\hline 8 & 8.6456 & 0.8815 & 7.4442 & 9.9510 & 1.7254 & 9.0068 \\
20 & 1.4456 & 0.9844 & 1.1150 & 4.1565 & 1.0974 & 3.2825 \\
29 & 0.8840 & 12.3323 & 9.6736 & 2.0189 & 12.9755 & 11.2258 \\
\hline
\end{tabular}


Figure 4 and 5 show graphical illustration of the increment of fault levels at sub-transient and transient conditions that provide a better view of the increment values. The increment in fault level at Bus 29 with low load is more compare to the increment in fault level at Bus 8 that has high load. In addition, Scenario 4 has the lowest fault current at Bus 20 for both sub-transient and transient conditions compared to other buses since DG is not connected to this bus. The fault level reduces significantly when the size of solar $\mathrm{PV}$ is evenly distributed at two different areas rather than located at one specific location.

\section{CONCLUSIONS}

This research work analyzes the impact of DG on the fault level, which is the short circuit current for IEEE 30 bus test system for different scenarios. The fault level is determined by varying the size and location of solar PV. The selection of DG location and level of penetration is important in minimizing the effects to short circuit current. In this research work, three phase symmetrical fault is applied at certain buses in the system based on the concentration of the load and the connection of DG. Based on the results, the fault current increases with the interconnection of DG to the existing distribution system. When solar PV penetration is higher, it causes the fault current to increase and the increment is even higher if the faulted bus is connected with solar PV. Furthermore, it can be compared that bus with lower load has a higher fault level than the bus with bigger load when solar PV is connected to these buses. In conclusions, short circuit current must be monitored analyzed through simulation before applying it to the utility network as it may lead to flashover and costly maintenance of primary equipment in the system.

\section{ACKNOWLEDGEMENT}

The research team would like to acknowledge UNITEN Bold Grant (10289176/B/9/2017/45) for providing the funding, facilities and making this research possible.

\section{REFERENCES}

[1] S. N. Afifi, H. Wang, G. A. Taylor, M. R. Irving. Impact of DFIG wind turbines on short circuit levels in distribution networks using ETAP. Power Engineering Conference (UPEC), 48th International Universities', Dublin, 2013: 1-4.

[2] A. Ali, F. A. Buderi, M. A. M. Hanafiah, Z. A. Baharudin. Assessment on the impact of distributed generation to the distribution network overcurrent protection in Malaysia. 2016 IEEE International Conference on Power and Energy (PECon), Melaka, Malaysia, 2016: 361-365.

[3] G. B. Narejo, F. Azeem, W. Azeem. Renewable energy-based power systems: models, indigenous analyses and design approaches. 2017 International Conference on Innovations in Electrical Engineering and Computational Technologies (ICIEECT). Karachi, India. 2017: 1-5.

[4] S. P. George, S. Ashok, M. N. Bandyopadhyay. Impact of distributed generation on protective relays. 2013 International Conference on Renewable Energy and Sustainable Energy (ICRESE). Coimbatore. 2013: 157-161.

[5] A. Abdel-Majeed, R. Viereck, F. Oechsle, M. Braun, S. Tenbohlen. Effects of Distributed Generators from Renewable Energy on the Protection System in Distribution Networks. Universities' Power Engineering Conference (UPEC), Proceedings of 2011 46th International. Soest, Germany. 2011: 1-6.

[6] F. M. Nuroglu, A. B. Arsoy. Voltage profile and short circuit analysis in distribution systems with DG. 2008 IEEE Canada Electric Power Conference. Vancouver, BC. 2008: 1-5.

[7] S. A. Hosseini, S. H. H. Sadeghi, A. Askarian-Abyaneh, A. Nasiri. Optimal placement and sizing of distributed generation sources considering network parameters and protection issues. 2014 International Conference on Renewable Energy Research and Application (ICRERA). Milwaukee, WI. 2014: 922-926.

[8] "S Chanda, A De. Congestion relief of contingent power network with evolutionary optimization algorithm. TELKOMNIKA (Telecommunication, Computing, Electronics and Control). 2012; 10(1): 1-8.

[9] J. P. R. Gomes, W. C. Boaventura, E. N. Cardoso, B. M. Lopes. Impact of integrating a Solar Power Plant in a distribution feeder considering short circuit events. 2015 IEEE 13th Brazilian Power Electronics Conference and 1st Southern Power Electronics Conference (COBEP/SPEC). Fortaleza. 2015: 1-5.

[10] M. Yasin, Zuhaila, N. Sam’ón, I. Aminudin, N. Salim, N. Mohamad, Hasmaini. Impact of Distributed Generation on the Fault Current in Power Distribution System. 2017 TELKOMNIKA Indonesian Journal of Electrical Engineering. 2017: 357-367.

[11] M. Q. Duong, N. T. N. Tran, G. N. Sava, M. Scripcariu. The impacts of distributed generation penetration into the power system. 2017 International Conference on Electromechanical and Power Systems (SIELMEN). Iasi, Romania. 2017: 295-301.

[12] R. R. Waqfi, M. Nour. Impact of PV and wind penetration into a distribution network using Etap. 2017 7th International Conference on Modeling, Simulation, and Applied Optimization (ICMSAO). Sharjah. 2017: 1-5.

[13] S. Ananwattanaporn, A. Ngaopitakkul. Impact of multi-Distributed generation on key parameter in distribution system. 10th International Conference on Advances in Power System Control, Operation \& Management (APSCOM 2015). Hong Kong. 2015: 1-6. 
[14] K. Balamurugan, D. Srinivasan, T. Reindl. Impact of Distributed Generation on Power Distribution Systems. 2011 PV Asia Pacific Conference. Energy Procedia. Singapore. 2012; 25: 93-100.

[15] Kejun Qian, Chengke Zhou, Yue Yuan, Xiaodan Shi, M. Allan. Analysis of the environmental benefits of Distributed Generation. 2008 IEEE Power and Energy Society General Meeting - Conversion and Delivery of Electrical Energy in the 21st Century. Pittsburgh, PA. 2008: 1-5.

[16] P. Mohammadi, H. El-Kishyky, M. Abdel-Akher, M. Abdel-Salam. The impacts of distributed generation on fault detection and voltage profile in power distribution networks. 2014 IEEE International Power Modulator and High Voltage Conference (IPMHVC). Santa Fe, NM. 2014: 191-196.

[17] S. Ghaemi, M. Abapour. Effect of Fault Current Limiter (FCL) on reliability and protection coordination of distribution system. 2016 24th Iranian Conference on Electrical Engineering (ICEE). Shiraz. 2016: 726-731.

[18] S.S. Wahid, M. S. Ramli, Z. A. Noorden, K. K. Hassan, S. A. Azli. A Review on Highlights and Feasibility Studies on Solar Energy Utilization in Malaysia. 2017 American Institute of Physic. Malaysia. 2017: 1-8.

[19] M. H. Athari, Z. Wang, S. H. Eylas. Time-series analysis of photovoltaic distributed generation impacts on a local distributed network. 2017 IEEE Manchester PowerTech. Manchester. 2017: 1-6.

[20] O. Ipinnimo, S. Chowdhury, S.P. Chowdhury, J. Mitra. A review of voltage dip mitigation techniques with distributed generation in electricity networks. 2013 In Electric Power Systems Research. 2013: 28-36.

[21] M. Karimi, H. Mokhlis, K. Naidu, S. Uddin, A.H.A. Bakar. Photovoltaic penetration issues and impacts in distribution network. 2016 A review, In Renewable and Sustainable Energy Reviews. 2016: 594-605.

[22] L. Mukwekwe, C. Venugopal, I. E. Davidson. A review of the impacts and mitigation strategies of high PV penetration in low voltage networks. 2017 IEEE PES PowerAfrica. Accra. 2017: 274-279.

[23] B. Hussain, S. M. Sharkh, S. Hussain. Impact studies of distributed generation on power quality and protection setup of an existing distribution network. SPEEDAM 2010. Pisa. 2010: 243-1246.

[24] Guidelines on Large Scale Solar Photovoltaic Plant for Connection to Electricity Networks. Large Scale Solar Photovoltaic Plant. Suruhanjaya Tenaga. 2017: 1 - 15. 